\title{
Fixed Point and Common Fixed Point Theorems on Ordered Cone b-Metric Spaces
}

\author{
Sahar Mohammad Abusalim and Mohd Salmi Md Noorani \\ School of Mathematical Sciences, Faculty of Science and Technology, Universiti Kebangsaan Malaysia, \\ 43600 Bangi, Selangor Darul Ehsan, Malaysia
}

Correspondence should be addressed to Sahar Mohammad Abusalim; saharabosalem@gmail.com

Received 28 February 2013; Accepted 18 April 2013

Academic Editor: Abdelghani Bellouquid

Copyright (C) 2013 S. M. Abusalim and M. S. M. Noorani. This is an open access article distributed under the Creative Commons Attribution License, which permits unrestricted use, distribution, and reproduction in any medium, provided the original work is properly cited.

\begin{abstract}
The concept of a cone b-metric space has been introduced recently as a generalization of a b-metric space and a cone metric space in 2011. The aim of this paper is to establish some fixed point and common fixed point theorems on ordered cone b-metric spaces. The proposed theorems expand and generalize several well-known comparable results in the literature to ordered cone b-metric spaces. Some supporting examples are given.
\end{abstract}

\section{Introduction}

Fixed point theory has attracted many researchers since 1922 with the admired Banach fixed point theorem. This theorem supplies a method for solving a variety of applied dilemma in mathematical sciences and engineering. A large literature on this subject exists, and this is a very active area of research at present. Banach contraction principle has been generalized in dissimilar directions in different spaces by mathematicians over the years; for more details on this and related topics, we refer to [1-6] and references therein.

In contemporary time, fixed point theory has evolved speedily in partially ordered cone metric spaces; that is, cone metric spaces equipped with a partial ordering, for some new results in ordered metric spaces see [7]. A coming early result in this bearing was constituted by Altun and Durmaz [8] under the condition of normality for cones. Then, Altun et al. [9] generalized the results of Altun and Durmaz [8] by omitting the assumption of normality condition for cones. Afterward, several authors have studied fixed point and common fixed point problems in ordered cone metric spaces; for more details see [10-17].

In 2011, Hussain and Shah [18] presented cone b-metric spaces as a generalization of b-metric spaces and cone metric spaces; for some new results in b-metric spaces see [19]. They not only constructed some topological properties in such spaces but also ameliorated some current results about KKM mappings in the setting of a cone b-metric space. After some time, many authors have been motivated to demonstrate fixed point theorems as well as common fixed point theorems for two or more mappings on cone b-metric spaces by the incipient work of Hussain and Shah [18] (see [20-23] and the references therein).

In [8], Altun and Durmaz proved the following results under the condition of normality for cones.

Theorem 1 (see [8]). Let $(X, \sqsubseteq)$ be a partially ordered set, suppose that there exists a cone metric $d$ in $X$ such that the cone metric space $(X, d)$ is complete, and let $P$ be a normal cone with normal constant $K$. Let $f: X \rightarrow X$ be a continuous and nondecreasing mapping with respect to $\sqsubseteq$. Suppose that the following three assertions hold:

(i) there exists $k \in[0,1)$ such that $d(f x, f y) \leq k d(x, y)$ for all $x, y \in X$ with $y \sqsubseteq x$;

(ii) there exists $x_{0} \in X$ such that $x_{0} \sqsubseteq f x_{0}$.

Then $f$ has a fixed point in $X$.

In [9], Altun et al. generalized the above theorem and proved it without normality condition for cones. 
Theorem 2 (see [9]). Let $(X, \sqsubseteq)$ be a partially ordered set and suppose that there exists a cone metric $d$ in $X$ such that the cone metric space $(X, d)$ is complete over a solid cone $P$. Let $f: X \rightarrow X$ be a continuous and nondecreasing mapping with respect to $\sqsubseteq$. Suppose that the following two assertions hold:

(i) there exist $k, l, r \in[0,1)$ with $k+2 l+2 r<1$ such that

$$
\begin{gathered}
d(f x, f y) \preceq k d(x, y)+l(d(f x, x)+d(f y, y)) \\
+r(d(f x, y)+d(f y, x))
\end{gathered}
$$

for all $x, y \in X$ with $y \sqsubseteq x$;

(ii) there exists $x_{0} \in X$ such that $x_{0} \sqsubseteq f x_{0}$.

Then $f$ has a fixed point in $X$.

Theorem 3 (see [9]). Let $(X$, 드) be a partially ordered set and suppose that there exists a cone metric $d$ in $X$ such that the cone metric space $(X, d)$ is complete over a solid cone $P$. Let $f: X \rightarrow X$ be a nondecreasing mapping with respect to 5 . Suppose that the following three assertions hold:

(i) there exist $k, l, r \in[0,1)$ with $k+2 l+2 r<1$ such that

$$
\begin{gathered}
d(f x, f y) \preceq k d(x, y)+l(d(f x, x)+d(f y, y)) \\
+r(d(f x, y)+d(f y, x))
\end{gathered}
$$

for all $x, y \in X$ with $y \sqsubseteq x$;

(ii) there exists $x_{0} \in X$ such that $x_{0} \sqsubseteq f x_{0}$;

(iii) if an increasing sequence $\left\{x_{n}\right\}$ converges to $x$ in $X$, then $x_{n} \sqsubseteq x$ for all $n$.

Then $f$ has a fixed point in $X$.

In the same paper, they also presented the following two common fixed point results in ordered cone metric spaces.

Theorem 4 (see [9]). Let $(X, \sqsubseteq$ ) be a partially ordered set and suppose that there exists a cone metric $d$ in $X$ such that the cone metric space $(X, d)$ is complete over a solid cone $P$. Let $f, g: X \rightarrow X$ be two weakly increasing mappings with respect to $\sqsubseteq$. Suppose that the following three assertions hold:

(i) there exist $k, l, r \in[0,1)$ with $k+2 l+2 r<1$ such that

$$
\begin{gathered}
d(f x, g y) \preceq k d(x, y)+l(d(x, f x)+d(y, g y)) \\
+r(d(y, f x)+d(x, g y))
\end{gathered}
$$

for all comparative $x, y \in X$;

(ii) $f$ or $g$ is continuous.

Then $f$ and $g$ have a common fixed point $x^{*} \in X$.

Theorem 5 (see [9]). Let $(X, \sqsubseteq$ ) be a partially ordered set and suppose that there exists a cone metric $d$ in $X$ such that the cone metric space $(X, d)$ is complete over a solid cone P. Let $f, g: X \rightarrow X$ be two weakly increasing mappings with respect to $\sqsubseteq$. Suppose that the following three assertions hold:

(i) there exist $k, l, r \in[0,1)$ with $k+2 l+2 r<1$ such that

$$
\begin{gathered}
d(f x, g y) \preceq k d(x, y)+l(d(x, f x)+d(y, g y)) \\
+r(d(y, f x)+d(x, g y))
\end{gathered}
$$

for all comparative $x, y \in X$;

(ii) if an increasing sequence $\left\{x_{n}\right\}$ converges to $x$ in $X$, then $x_{n} \sqsubseteq x$ for all $n$.

Then $f$ and $g$ have a common fixed point $x^{*} \in X$.

In this paper, we prove some fixed point and common fixed point theorems on ordered cone b-metric spaces. Our results extend and generalize several well-known comparable results in the literature to ordered cone b-metric spaces. Throughout this paper, we do not impose the normality condition for the cones, but the only assumption is that the cone $P$ is solid, that is, int $P \neq \emptyset$.

The following definitions and results shall be needed in the sequel.

Let $E$ be a real Banach space and $\theta$ denotes the zero element in $E$. A cone $P$ is a subset of $E$ such that

(1) $P$ is nonempty closed set and $P \neq\{\theta\}$;

(2) if $a, b$ are nonnegative real numbers and $x, y \in P$, then $a x+b y \in P$

(3) $x \in P$ and $-x \in P$ imply $x=\theta$.

For any cone $P \subset E$, the partial ordering $\preceq$ with respect to $P$ is defined by $x \preceq y$ if and only if $y-x \in P$. The notation of $\prec$ stands for $x \preceq y$ but $x \neq y$. Also, we use $x \ll y$ to indicate that $y-x \in \operatorname{int} P$, where int $P$ denotes the interior of $P$. A cone $P$ is called normal if there exists the number $K$ such that

$$
\theta \preceq x \preceq y \Longrightarrow\|x\| \leq K\|y\|,
$$

for all $x, y \in E$. The least positive number $K$ satisfying the above condition is called the normal constant of $P$.

Definition 6 (see [18]). Let $X$ be a nonempty set and $E$ a real Banach space equipped with the partial ordering $\preceq$ with respect to the cone $P$. A vector-valued function $d: X \times X \rightarrow$ $E$ is said to be a cone b-metric function on $X$ with the constant $s \geq 1$ if the following conditions are satisfied:

(1) $\theta \preceq d(x, y)$ for all $x, y \in X$ and $d(x, y)=\theta$ if and only if $x=y$;

(2) $d(x, y)=d(y, x)$ for all $x, y \in X$;

(3) $d(x, y) \preceq s(d(x, y)+d(y, z))$ for all $x, y, z \in X$.

Then pair $(X, d)$ is called a cone b-metric space (or a cone metric type space); we shall use the first mentioned term.

Observe that if $s=1$, then the ordinary triangle inequality in a cone metric space is satisfied; however, it does not hold true when $s>1$. Thus the class of cone b-metric spaces is 
effectively larger than that of the ordinary cone metric spaces. That is, every cone metric space is a cone b-metric space, but the converse need not be true. The following examples show the above remarks.

Example 7. Let $X=\{-1,0,1\}, E=\mathbb{R}^{2}$, and $P=\{(x, y): x \geq$ $0, y \geq 0\}$. Define $d: X \times X \rightarrow P$ by $d(x, y)=d(y, x)$ for all $x, y \in X, d(x, x)=\theta, x \in X$, and $d(-1,0)=$ $(3,3), d(-1,1)=d(0,1)=(1,1)$. Then $(X, d)$ is a complete cone $b$-metric space but the triangle inequality is not satisfied. Indeed, we have that $d(-1,1)+d(1,0)=(1,1)+(1,1)=$ $(2,2) \prec(3,3)=d(-1,0)$. It is not hard to verify that $s=3 / 2$.

Example 8. Let $X=\mathbb{R}, E=\mathbb{R}^{2}$, and $P=\{(x, y) \in E$ : $x \geq 0, y \geq 0\}$. Define $d: X \times X \rightarrow E$ by $d(x, y)=$ $\left(|x-y|^{2},|x-y|^{2}\right)$. Then, it is easy to see that $(X, d)$ is a cone b-metric space with the coefficient $s=2$. But it is not a cone metric spaces since the triangle inequality is not satisfied.

Definition 9 (see [18]). Let $(X, d)$ be a cone b-metric space, $\left\{x_{n}\right\}$ a sequence in $X$ and $x \in X$.

(1) For all $c \in E$ with $\theta \ll c$, if there exists a positive integer $N$ such that $d\left(x_{n}, x\right) \ll c$ for all $n>N$, then $x_{n}$ is said to be convergent and $x$ is the limit of $\left\{x_{n}\right\}$. One denotes this by $x_{n} \rightarrow x$.

(2) For all $c \in E$ with $\theta \ll c$, if there exists a positive integer $N$ such that $d\left(x_{n}, x_{m}\right) \ll c$ for all $n, m>N$, then $\left\{x_{n}\right\}$ is called a Cauchy sequence in $X$.

(3) A cone metric space $(X, d)$ is called complete if every Cauchy sequence in $X$ is convergent.

The following lemma is useful in our work.

Lemma 10 (see [24]).

(1) If $E$ is a real Banach space with a cone $P$ and $a \preceq \lambda a$ where $a \in P$ and $0 \leq \lambda<1$, then $a=\theta$.

(2) If $c \in \operatorname{int} P, \theta \preceq a_{n}$, and $a_{n} \rightarrow \theta$, then there exists $a$ positive integer $N$ such that $a_{n} \ll c$ for all $n \geq N$.

(3) If $a \preceq b$ and $b \ll c$, then $a \ll c$.

(4) If $\theta \preceq u \ll c$ for each $\theta \ll c$, then $u=\theta$.

\section{Fixed Point Results}

In this section, we prove some fixed point theorems on ordered cone b-metric space. We begin with a simple but a useful lemma.

Lemma 11. Let $\left\{x_{n}\right\}$ be a sequence in a cone b-metric space $(X, d)$ with the coefficient $s \geq 1$ relative to a solid cone $P$ such that

$$
d\left(x_{n}, x_{n+1}\right) \preceq h d\left(x_{n-1}, x_{n}\right),
$$

where $h \in[0,1 / s)$ and $n=1,2, \ldots$. Then $\left\{x_{n}\right\}$ is a Cauchy sequence in $(X, d)$.
Proof. Let $m>n \geq 1$. It follows that

$$
\begin{gathered}
d\left(x_{n}, x_{m}\right) \preceq s d\left(x_{n}, x_{n+1}\right)+s^{2} d\left(x_{n+1}, x_{n+2}\right) \\
+\cdots+s^{m-n} d\left(x_{m-1}, x_{m}\right) .
\end{gathered}
$$

Now, (6) and $s h<1$ imply that

$$
\begin{aligned}
d\left(x_{n}, x_{m}\right) \preceq & s d\left(x_{n}, x_{n+1}\right)+s^{2} d\left(x_{n+1}, x_{n+2}\right) \\
& +\cdots+s^{m-n} d\left(x_{m-1}, x_{m}\right) \\
\preceq & s h^{n} d\left(x_{0}, x_{1}\right)+s^{2} h^{n+1} d\left(x_{0}, x_{1}\right) \\
& +\cdots+s^{m-n} h^{m-1} d\left(x_{0}, x_{1}\right) \\
= & \left(s h^{n}+s^{2} h^{n+1}+\cdots+s^{m-n} h^{m-1}\right) d\left(x_{0}, x_{1}\right) \\
= & s h^{n}\left(1+s h+(s h)^{2}+\cdots+(s h)^{m-n-1}\right) d\left(x_{0}, x_{1}\right) \\
\preceq & \frac{s h^{n}}{1-s h} d\left(x_{0}, x_{1}\right) \longrightarrow \theta \quad \text { as } n \longrightarrow \infty .
\end{aligned}
$$

According to Lemma 10(2), and for any $c \in E$ with $c \gg \theta$, there exists $N_{0} \in \mathbb{N}$ such that for any $n>N_{0}$, $\left(s h^{n} /(1-\right.$ $\operatorname{sh}) d\left(x_{0}, x_{1}\right) \ll c$. Furthermore, from (8) and for any $m>$ $n>N_{0}$, Lemma 10(3) shows that

$$
d\left(x_{n}, x_{m}\right) \ll c .
$$

Hence, by Definition 9(2) $\left\{x_{n}\right\}$ is a Cauchy sequence in $X$.

Theorem 12. Let $(X, \sqsubseteq)$ be a partially ordered set and suppose that there exists a cone $b$-metric $d$ in $X$ such that the cone $b$-metric space $(X, d)$ is complete with the coefficient $s \geq 1$ relative to a solid cone $P$. Let $f: X \rightarrow X$ be a continuous and nondecreasing mapping with respect to $\sqsubseteq$. Suppose that the following three assertions hold:

(i) there exist $a_{i}, i=1, \ldots, 5$, such that $2 s a_{1}+(s+1)\left(a_{2}+\right.$ $\left.a_{3}\right)+\left(s^{2}+s\right)\left(a_{4}+a_{5}\right)<2$ with $\sum_{i=1}^{5} a_{i}<1$,

$$
\begin{aligned}
& d(f x, f y) \preceq a_{1} d(x, y)+a_{2} d(f x, x)+a_{3} d(f y, y) \\
& +a_{4} d(f x, y)+a_{5} d(f y, x)
\end{aligned}
$$

for all $x, y \in X$ with $y \sqsubseteq x$;

(ii) there exists $x_{0} \in X$ such that $x_{0} \sqsubseteq f x_{0}$.

Then $f$ has a fixed point $x^{*} \in X$.

Proof. If $x_{0}=f x_{0}$, then the proof is finished. Suppose that $x_{0} \neq f x_{0}$. Since $x_{0} \sqsubseteq f x_{0}$ and $f$ is nondecreasing with respect 
to $\sqsubseteq$, we obtain by induction that $x_{0} \sqsubseteq f x_{0}=x_{1} \sqsubseteq f^{1} x_{0}=$ $x_{2} \sqsubseteq \cdots \sqsubseteq f^{n-1} x_{0}=x_{n} \sqsubseteq f^{n} x_{0}=x_{n+1} \sqsubseteq \cdots$. Then we have,

$$
\begin{aligned}
d\left(x_{n+1}, x_{n}\right)= & d\left(f^{n} x_{0}, f^{n-1} x_{0}\right) \\
= & d\left(f\left(f^{n-1} x_{0}\right), f\left(f^{n-2} x_{0}\right)\right) \\
\leq & a_{1} d\left(f^{n-1} x_{0}, f^{n-2} x_{0}\right)+a_{2} d\left(f^{n-1} x_{0}, f^{n-2} x_{0}\right) \\
& +a_{3} d\left(f^{n} x_{0}, f^{n-1} x_{0}\right) \\
& +a_{4} d\left(f^{n} x_{0}, f^{n-2} x_{0}\right)+a_{5} d\left(f^{n-1} x_{0}, f^{n-1} x_{0}\right) \\
= & a_{1} d\left(x_{n}, x_{n-1}\right)+a_{2} d\left(x_{n+1}, x_{n}\right)+a_{3} d\left(x_{n}, x_{n-1}\right) \\
& +a_{4} d\left(x_{n+1}, x_{n-1}\right)+a_{5} d\left(x_{n}, x_{n}\right) \\
\leq & a_{1} d\left(x_{n}, x_{n-1}\right)+a_{2} d\left(x_{n+1}, x_{n}\right)+a_{3} d\left(x_{n}, x_{n-1}\right) \\
& +s a_{4}\left(d\left(x_{n+1}, x_{n}\right)+d\left(x_{n}, x_{n-1}\right)\right) .
\end{aligned}
$$

Then, one can assert that

$$
\begin{aligned}
d\left(x_{n+1}, x_{n}\right) \preceq & \left(a_{1}+a_{3}+s a_{4}\right) d\left(x_{n}, x_{n-1}\right) \\
& +\left(a_{2}+s a_{4}\right) d\left(x_{n+1}, x_{n}\right) .
\end{aligned}
$$

On the other hand, we have

$$
\begin{aligned}
d\left(x_{n}, x_{n+1}\right)= & d\left(f^{n-1} x_{0}, f^{n} x_{0}\right) \\
= & d\left(f\left(f^{n-2} x_{0}\right), f\left(f^{n-1} x_{0}\right)\right) \\
\leq & a_{1} d\left(f^{n-2} x_{0}, f^{n-1} x_{0}\right)+a_{2} d\left(f^{n-2} x_{0}, f^{n-1} x_{0}\right) \\
& +a_{3} d\left(f^{n-1} x_{0}, f^{n} x_{0}\right) \\
& +a_{4} d\left(f^{n-1} x_{0}, f^{n-1} x_{0}\right)+a_{5} d\left(f^{n} x_{0}, f^{n-2} x_{0}\right) \\
= & a_{1} d\left(x_{n}, x_{n-1}\right)+a_{2} d\left(x_{n}, x_{n-1}\right)+a_{3} d\left(x_{n+1}, x_{n}\right) \\
& +a_{4} d\left(x_{n}, x_{n}\right)+a_{5} d\left(x_{n+1}, x_{n-1}\right) \\
\preceq & a_{1} d\left(x_{n}, x_{n-1}\right)+a_{2} d\left(x_{n}, x_{n-1}\right)+a_{3} d\left(x_{n+1}, x_{n}\right) \\
& +s a_{5}\left(d\left(x_{n+1}, x_{n}\right)+d\left(x_{n}, x_{n-1}\right)\right) .
\end{aligned}
$$

Then, one can assert that

$$
\begin{aligned}
d\left(x_{n+1}, x_{n}\right) \preceq & \left(a_{1}+a_{2}+s a_{5}\right) d\left(x_{n}, x_{n-1}\right) \\
& +\left(a_{3}+s a_{5}\right) d\left(x_{n+1}, x_{n}\right) .
\end{aligned}
$$

Adding (12) and (14), we get

$$
\begin{aligned}
d\left(x_{n+1}, x_{n}\right) & \preceq \frac{2 a_{1}+a_{2}+a_{3}+s a_{4}+s a_{5}}{2-\left(a_{2}+a_{3}+s a_{4}+s a_{5}\right)} d\left(x_{n}, x_{n-1}\right) \\
& =\lambda d\left(x_{n}, x_{n-1}\right),
\end{aligned}
$$

where $\lambda=\left(2 a_{1}+a_{2}+a_{3}+s a_{4}+s a_{5}\right) /\left(2-\left(a_{2}+a_{3}+s a_{4}+\right.\right.$ $\left.\left.s a_{5}\right)\right)<1 / s$. According to Lemma 11 , we have $\left\{x_{n}\right\}$ is a Cauchy sequence in $X$. Since $X$ is complete, there exists $x^{*} \in X$ such that $x_{n} \rightarrow x^{*}$. Since $f$ is continuous, then $x^{*}=\lim x_{n+1}=$ $\lim f^{n} x_{0}=\lim f\left(f^{n-1} x_{0}\right)=f\left(\lim f^{n-1} x_{0}\right)=f\left(\lim x_{n}\right)=$ $f\left(x^{*}\right)$. Therefore, $x^{*}$ is a fixed point of $f$.

If we use condition (iii) instead of the continuity of $f$ in Theorem 12, we have the following result.

Theorem 13. Let $(X, \sqsubseteq)$ be a partially ordered set and suppose that there exists a cone $b$-metric $d$ in $X$ such that the cone $b$ metric space $(X, d)$ is complete with the coefficient $s \geq 1$ relative to a solid cone $P$. Let $f: X \rightarrow X$ be a nondecreasing mapping with respect to $\sqsubseteq$. Suppose that the following three assertions hold:

(i) there exist $a_{i}, i=1, \ldots, 5$, such that $2 s a_{1}+(s+1)\left(a_{2}+\right.$ $\left.a_{3}\right)+\left(s^{2}+s\right)\left(a_{4}+a_{5}\right)<2$ with $\sum_{i=1}^{5} a_{i}<1$,

$$
\begin{aligned}
d(f x, f y) \preceq & a_{1} d(x, y)+a_{2} d(f x, x)+a_{3} d(f y, y) \\
& +a_{4} d(f x, y)+a_{5} d(f y, x)
\end{aligned}
$$

for all $x, y \in X$ with $y \sqsubseteq x$;

(ii) there exists $x_{0} \in X$ such that $x_{0} \sqsubseteq f x_{0}$;

(iii) if an increasing sequence $\left\{x_{n}\right\}$ converges to $x$ in $X$, then $x_{n} \sqsubseteq x$ for all $n$.

Then $f$ has a fixed point $x^{*} \in X$.

Proof. As in the Theorem 12, we can construct an increasing sequence $\left\{x_{n}\right\}$ and prove that there exists $x^{*} \in X$ such that $x_{n} \rightarrow x^{*}$. Now, condition (iii) implies $x_{n} \sqsubseteq x^{*}$ for all $n$. Therefore, we can use condition (i) and so

$$
\begin{aligned}
d\left(f x_{n}, f x^{*}\right) \preceq & a_{1} d\left(x_{n}, x^{*}\right)+a_{2} d\left(f x_{n}, x_{n}\right)+a_{3} d\left(f x^{*}, x^{*}\right) \\
& +a_{4} d\left(f x_{n}, x^{*}\right)+a_{5} d\left(f x^{*}, x_{n}\right) .
\end{aligned}
$$

Taking $n \rightarrow \infty$, we have $d\left(x^{*}, f x^{*}\right) \preceq\left(a_{3}+a_{5}\right) d\left(x^{*}, f x^{*}\right)$ $d\left(x^{*}, f x^{*}\right)$. Since $\left(a_{3}+a_{5}\right)<1$, Lemma 10(1) shows that $d\left(x^{*}, f x^{*}\right)=\theta$; that is, $x^{*}=f x^{*}$. Therefore $x^{*}$ is a fixed point of $f$.

\section{Common Fixed Point Results}

Now, we give two common fixed point theorems on ordered cone b-metric spaces. We need the following definition.

Definition 14 (see [9]). Let $(X, \sqsubseteq)$ be a partially ordered set. Two mappings $f, g: X \rightarrow X$ are said to be weakly increasing if $f x \sqsubseteq g f x$ and $g x \sqsubseteq f g x$ hold for all $x \in X$.

Theorem 15. Let $(X, \sqsubseteq)$ be a partially ordered set and suppose that there exists a cone $b$-metric $d$ in $X$ such that the cone $b$ metric space $(X, d)$ is complete with the coefficient $s \geq 1$ relative to a solid cone $P$. Let $f, g: X \rightarrow X$ be two weakly increasing mappings with respect to $\sqsubseteq$. Suppose that the following three assertions hold: 
(i) there exist $a_{i}, i=1, \ldots, 5$, such that $2 s a_{1}+(s+1)\left(a_{2}+\right.$ $\left.a_{3}\right)+\left(s^{2}+s\right)\left(a_{4}+a_{5}\right)<2$ with $\sum_{i=1}^{5} a_{i}<1$,

$$
\begin{aligned}
d(f x, g y) \leq & a_{1} d(x, y)+a_{2} d(x, f x)+a_{3} d(y, g y) \\
& +a_{4} d(y, f x)+a_{5} d(x, g y)
\end{aligned}
$$

for all comparative $x, y \in X$;

(ii) $f$ or $g$ is continuous.

Then $f$ and $g$ have a common fixed point $x^{*} \in X$.

Proof. Let $x_{0}$ be an arbitrary point of $X$ and define a sequence $\left\{x_{n}\right\}$ in $X$ as follows: $x_{2 n+1}=f x_{2 n}$ and $x_{2 n+2}=g x_{2 n+1}$ for all $n>0$. Note that, since $f$ and $g$ are weakly increasing, we have $x_{1}=f x_{0} \sqsubseteq g f x_{0}=g x_{1}=x_{2}$ and $x_{2}=g x_{1} \sqsubseteq f g x_{1}=f x_{2}=$ $x_{3}$, and continuing this process we have $x_{1} \sqsubseteq x_{2} \sqsubseteq \cdots \sqsubseteq x_{n} \sqsubseteq$ $x_{n+1} \sqsubseteq \cdots$. That is, the sequence $\left\{x_{n}\right\}$ is nondecreasing. Now, since $x_{2 n}$ and $x_{2 n+1}$ are comparative, we can use the inequality (18), and then we have

$$
\begin{aligned}
d\left(x_{2 n+1}, x_{2 n+2}\right)= & d\left(f x_{2 n}, g x_{2 n+1}\right) \\
\leq & a_{1} d\left(x_{2 n}, x_{2 n+1}\right)+a_{2} d\left(x_{2 n}, f x_{2 n}\right) \\
& +a_{3} d\left(x_{2 n+1}, g x_{2 n+1}\right) \\
& +a_{4} d\left(x_{2 n+1}, f x_{2 n}\right)+a_{5} d\left(x_{2 n}, g x_{2 n+1}\right) \\
\leq & a_{1} d\left(x_{2 n}, x_{2 n+1}\right)+a_{2} d\left(x_{2 n}, x_{2 n+1}\right) \\
& +a_{3} d\left(x_{2 n+1}, x_{2 n+2}\right) \\
& +a_{4} d\left(x_{2 n+1}, x_{2 n+1}\right)+a_{5} d\left(x_{2 n}, x_{2 n+2}\right) \\
\leq & \left(a_{1}+a_{2}\right) d\left(x_{2 n}, x_{2 n+1}\right)+a_{3} d\left(x_{2 n+1}, x_{2 n+2}\right) \\
& +s a_{5}\left(d\left(x_{2 n}, x_{2 n+1}\right)+d\left(x_{2 n+1}, x_{2 n+2}\right)\right) \\
= & \left(a_{1}+a_{2}+s a_{5}\right) d\left(x_{2 n}, x_{2 n+1}\right) \\
& +\left(a_{3}+s a_{5}\right) d\left(x_{2 n+1}, x_{2 n+2}\right) .
\end{aligned}
$$

Hence,

$$
\begin{aligned}
& \left(1-\left(a_{3}+s a_{5}\right)\right) d\left(x_{2 n+1}, x_{2 n+2}\right) \\
& \quad \leq\left(a_{1}+a_{2}+s a_{5}\right) d\left(x_{2 n}, x_{2 n+1}\right) .
\end{aligned}
$$

On the other hand and by symmetry we have

$$
\begin{aligned}
d\left(x_{2 n+2}, x_{2 n+1}\right)= & d\left(g x_{2 n+1}, f x_{2 n}\right) \\
\leq & a_{1} d\left(x_{2 n+1}, x_{2 n}\right)+a_{2} d\left(x_{2 n+1}, g x_{2 n+1}\right) \\
& +a_{3} d\left(x_{2 n}, f x_{2 n}\right) \\
& +a_{4} d\left(x_{2 n}, g x_{2 n+1}\right)+a_{5} d\left(x_{2 n+1}, f x_{2 n}\right)
\end{aligned}
$$

$$
\begin{aligned}
\leq & a_{1} d\left(x_{2 n+1}, x_{2 n}\right)+a_{2} d\left(x_{2 n+1}, x_{2 n+2}\right) \\
& +a_{3} d\left(x_{2 n}, x_{2 n+1}\right) \\
& +a_{4} d\left(x_{2 n}, x_{2 n+2}\right)+a_{5} d\left(x_{2 n+1}, x_{2 n+1}\right) \\
\leq & \left(a_{1}+a_{3}\right) d\left(x_{2 n}, x_{2 n+1}\right)+a_{2} d\left(x_{2 n+1}, x_{2 n+2}\right) \\
& +s a_{4}\left(d\left(x_{2 n}, x_{2 n+1}\right)+d\left(x_{2 n+1}, x_{2 n+2}\right)\right) \\
= & \left(a_{1}+a_{3}+s a_{4}\right) d\left(x_{2 n}, x_{2 n+1}\right) \\
& +\left(a_{2}+s a_{4}\right) d\left(x_{2 n+1}, x_{2 n+2}\right) .
\end{aligned}
$$

Hence,

$$
\begin{aligned}
& \left(1-\left(a_{2}+s a_{4}\right)\right) d\left(x_{2 n+2}, x_{2 n+1}\right) \\
& \quad \preceq\left(a_{1}+a_{3}+s a_{4}\right) d\left(x_{2 n}, x_{2 n+1}\right) .
\end{aligned}
$$

Adding inequalities (20) and (22), we get

$$
\begin{aligned}
d\left(x_{2 n+1}, x_{2 n+2}\right) & \leq \frac{\left(2 a_{1}+a_{2}+a_{3}+s a_{4}+s a_{5}\right)}{2-\left(a_{2}+a_{3}+s a_{4}+s a_{5}\right)} d\left(x_{2 n}, x_{2 n+1}\right) \\
& =\lambda d\left(x_{2 n}, x_{2 n+1}\right),
\end{aligned}
$$

where $\lambda=\left(2 a_{1}+a_{2}+a_{3}+s a_{4}+s a_{5}\right) /\left(2-\left(a_{2}+a_{3}+s a_{4}+s a_{5}\right)\right)<$ $1 / s$. Similarly, it can be shown that

$$
d\left(x_{2 n+3}, x_{2 n+2}\right) \leq \lambda d\left(x_{2 n+}, x_{2 n+2}\right) .
$$

Therefore,

$$
d\left(x_{n+1}, x_{n+2}\right) \leq \lambda d\left(x_{n}, x_{n+1}\right) .
$$

According to Lemma 11, we have $\left\{x_{n}\right\}$ is a Cauchy sequence in $X$. Since $X$ is complete, there exists $x^{*} \in X$ such that $x_{n} \rightarrow$ $x^{*}$. Suppose that $f$ is continuous. Then, $x^{*}=\lim x_{n+1}=$ $\lim f^{n} x_{0}=\lim f\left(f^{n-1} x_{0}\right)=f\left(\lim f^{n-1} x_{0}\right)=f\left(\lim x_{n}\right)=$ $f\left(x^{*}\right)$. Therefore, $x^{*}$ is a fixed point of $f$. Now, we need to show that $x^{*}$ is a fixed point of $g$. Since $x^{*} \sqsubseteq x^{*}$, we can use the inequality (18) for $x=y=x^{*}$. Then we have

$$
\begin{aligned}
d\left(f x^{*}, g x^{*}\right) \leq & a_{1} d\left(x^{*}, x^{*}\right)+a_{2} d\left(x^{*}, f x^{*}\right)+a_{3} d\left(x^{*}, g x^{*}\right) \\
& +a_{4} d\left(x^{*}, f x^{*}\right)+a_{5} d\left(x^{*}, g x^{*}\right) \\
= & a_{1} d\left(x^{*}, x^{*}\right)+a_{2} d\left(x^{*}, x^{*}\right)+a_{3} d\left(x^{*}, g x^{*}\right) \\
& +a_{4} d\left(x^{*}, x^{*}\right)+a_{5} d\left(x^{*}, g x^{*}\right) \\
= & a_{3} d\left(x^{*}, g x^{*}\right)+a_{5} d\left(x^{*}, g x^{*}\right) \\
= & \left(a_{3}+a_{5}\right) d\left(x^{*}, g x^{*}\right) .
\end{aligned}
$$

Hence,

$$
d\left(x^{*}, g x^{*}\right) \leq\left(a_{3}+a_{5}\right) d\left(x^{*}, g x^{*}\right) .
$$

Since $\left(a_{3}+a_{5}\right)<1$, Lemma 10(1) shows that $d\left(x^{*}, g x^{*}\right)=\theta$; that is, $x^{*}=g x^{*}$. Therefore $x^{*}$ is a fixed point of $g$. Therefore, $f$ and $g$ have a common fixed point. The proof is similar when $g$ is a continuous mapping. 
Theorem 16. Let $(X, \sqsubseteq)$ be a partially ordered set and suppose that there exists a cone $b$-metric $d$ in $X$ such that the cone $b$ metric space $(X, d)$ is complete with the coefficient $s \geq 1$ relative to a solid cone $P$. Let $f, g: X \rightarrow X$ be two weakly increasing mappings with respect to $\sqsubseteq$. Suppose that the following three assertions hold:

(i) there exist $a_{i}, i=1, \ldots, 5$ such that $2 s a_{1}+(s+1)\left(a_{2}+\right.$ $\left.a_{3}\right)+\left(s^{2}+s\right)\left(a_{4}+a_{5}\right)<2$ with $\sum_{i=1}^{5} a_{i}<1$,

$$
\begin{aligned}
d(f x, g y) \preceq & a_{1} d(x, y)+a_{2} d(x, f x) \\
& +a_{3} d(y, g y)+a_{4} d(y, f x)+a_{5} d(x, g y),
\end{aligned}
$$

for all comparative $x, y \in X$;

(ii) if an increasing sequence $\left\{x_{n}\right\}$ converges to $x$ in $X$, then $x_{n} \sqsubseteq x$ for all $n$.

Then $f$ and $g$ have a common fixed point $x^{*} \in X$.

Proof. As in Theorem 15, we can construct an increasing sequence $\left\{x_{n}\right\}$ and prove that there exists $x^{*} \in X$ such that $x_{n} \rightarrow x^{*}$, also; by the construction of $x_{n}, g x_{n} \rightarrow x^{*}$. Now, condition (iii) implies $x_{n} \sqsubseteq x^{*}$ for all $n$. Putting $x=x^{*}$ and $y=x_{n}$ in (28), we get

$$
\begin{aligned}
d\left(f x^{*}, g x_{n}\right) \leq & a_{1} d\left(x^{*}, x_{n}\right)+a_{2} d\left(x^{*}, f x^{*}\right) \\
& +a_{3} d\left(x_{n}, g x_{n}\right) \\
& +a_{4} d\left(x_{n}, f x^{*}\right)+a_{5} d\left(x^{*}, g x_{n}\right) \\
= & a_{1} d\left(x_{n}, x^{*}\right)+a_{2} d\left(f x^{*}, x^{*}\right) \\
& +a_{3} d\left(x_{n}, g x_{n}\right) \\
& +a_{4} d\left(x_{n}, f x^{*}\right)+a_{5} d\left(g x_{n}, x^{*}\right) \\
\leq & a_{1} d\left(x_{n}, x^{*}\right) \\
& +a_{2}\left(d\left(f x^{*}, g x_{n}\right)+d\left(g x_{n}, x^{*}\right)\right) \\
& +a_{3}\left(d\left(x_{n}, x^{*}\right)+d\left(x^{*}, g x_{n}\right)\right) \\
& +a_{4}\left(d\left(x_{n}, x^{*}\right)+d\left(x^{*}, g x_{n}\right)\right. \\
& \left.\quad+d\left(g x_{n}, f x^{*}\right)\right) \\
& +a_{5} d\left(g x_{n}, x^{*}\right) \\
= & \left(a_{1}+a_{3}+a_{4}\right) d\left(x_{n}, x^{*}\right) \\
& +\left(a_{2}+a_{3}+a_{4}+a_{5}\right) d\left(g x_{n}, x^{*}\right) \\
& +\left(a_{2}+a_{4}\right) d\left(f x^{*}, g x_{n}\right) .
\end{aligned}
$$

Hence,

$$
\begin{aligned}
d\left(f x^{*}, g x_{n}\right) \preceq & \frac{a_{1}+a_{3}+a_{4}}{1-\left(a_{2}+a_{4}\right)} d\left(x_{n}, x^{*}\right) \\
& +\frac{a_{2}+a_{3}+a_{4}+a_{5}}{1-\left(a_{2}+a_{4}\right)} d\left(g x_{n}, x^{*}\right) .
\end{aligned}
$$

Since $x_{n} \rightarrow x^{*}$ and $g x_{n} \rightarrow x^{*}$, then by Definition 9(1) and for $c \gg \theta$ there exists $N_{0} \in \mathbb{N}$ such that for all $n>N_{0}$, $d\left(x_{n}, x^{*}\right) \ll c\left(1-\left(a_{2}+a_{4}\right)\right) / 2\left(a_{1}+a_{3}+a_{4}\right)$, and $d\left(g x_{n}, x^{*}\right) \ll$ $c\left(1-\left(a_{2}+a_{4}\right)\right) / 2\left(a_{2}+a_{3}+a_{4}+a_{5}\right)$. Then we have

$$
\begin{aligned}
d\left(g x_{n}, f x^{*}\right)= & d\left(f x^{*}, g x_{n}\right) \\
\preceq & \frac{a_{1}+a_{3}+a_{4}}{1-\left(a_{2}+a_{4}\right)} d\left(x_{n}, x^{*}\right) \\
& +\frac{a_{2}+a_{3}+a_{4}+a_{5}}{1-\left(a_{2}+a_{4}\right)} d\left(g x_{n}, x^{*}\right) \\
\ll & \frac{a_{1}+a_{3}+a_{4}}{1-\left(a_{2}+a_{4}\right)} \frac{c\left(1-\left(a_{2}+a_{4}\right)\right)}{2\left(a_{1}+a_{3}+a_{4}\right)} \\
& +\frac{a_{2}+a_{3}+a_{4}+a_{5}}{1-\left(a_{2}+a_{4}\right)} \frac{c\left(1-\left(a_{2}+a_{4}\right)\right)}{2\left(a_{2}+a_{3}+a_{4}+a_{5}\right)} \\
= & \frac{c}{2}+\frac{c}{2} \\
= & c .
\end{aligned}
$$

Now again, according to Definition 9(1) it follows that $g x_{n} \rightarrow f x^{*}$. It follows that $f x^{*}=x^{*}$. In a similar way and using that $x^{*} \sqsubseteq x^{*}$, we can prove that $g x^{*}=x^{*}$. Therefore, $f$ and $g$ have a common fixed point.

Now, we present two examples to illustrate our results. In the first example (the case of a normal cone), the conditions of Theorem 12 are fulfilled, but Theorem 2 of Altun et al. [9, Theorem 12] cannot be applied. In the second example (the case of a nonnormal cone), the conditions of Theorem 12 are fulfilled, but Theorem 3 of Altun et al. [9, Theorem 13] cannot be applied.

Example 17. Let $X=[0,1]$ endowed with the standard order and $E=\mathbb{R}^{2}$ and let $P=\{(x, y): x, y \geq 0\}$. Define $d: X \times X \rightarrow E$ as in Example 8. Define $f: X \rightarrow X$ by $f(x)=x^{2} / 6$. Then $f$ is a continuous and nondecreasing mapping with respect to $\sqsubseteq$. Then we have

$$
\begin{aligned}
d(f x, f y) & =d\left(\frac{x^{2}}{6}, \frac{y^{2}}{6}\right) \\
& =\left(\left|\frac{x^{2}}{6}-\frac{y^{2}}{6}\right|^{2},\left|\frac{x^{2}}{6}-\frac{y^{2}}{6}\right|^{2}\right) \\
& =\frac{1}{36}|x+y|^{2}\left(|x-y|^{2},|x-y|^{2}\right) \\
& \preceq \frac{4}{36}\left(|x-y|^{2},|x-y|^{2}\right) \\
& \preceq \frac{4}{36} d(x, y),
\end{aligned}
$$

where $a_{1}=4 / 36, a_{2}=a_{3}=a_{4}=a_{5}=0$. It is clear that the conditions of Theorem 12 are satisfied. Therefore, $f$ has a fixed point $x=0$. 
Example 18. Let $X=[0, \infty)$ endowed with the standard order and $E=C_{\mathbb{R}}^{1}[0,1]$ with $\|u\|=\|u\|_{\infty}+\left\|u^{\prime}\right\|_{\infty}, u \in E$ and let $P=\{u \in E: u(t) \geq 0$ on $[0,1]\}$. It is well known that this cone is solid, but it is not normal. Define a cone metric $d: X \times$ $X \rightarrow E$ by $d(x, y)(t)=|x-y|^{2} e^{t}$. Then $(X, d)$ is a complete cone b-metric space with the coefficient $s=2$. Let us define $f: X \rightarrow X$ by $f(x)=x / 2$. Then $f$ is a continuous and nondecreasing mapping with respect to $\sqsubseteq$. Then we have $f$ is an increasing mapping; also we have

$$
\begin{aligned}
d(f x, f y)(t) & =\left|\frac{1}{2} x-\frac{1}{2} y\right|^{2} e^{t} \\
& =\frac{1}{4}|x-y|^{2} e^{t} \\
& \leq \frac{1}{4}|x-y|^{2} e^{t}+\frac{1}{5}\left|\frac{x}{2}\right|^{2} e^{t} \\
& \leq \frac{1}{4} d(x, y)(t)+\frac{1}{5} d(f x, x)(t),
\end{aligned}
$$

where $a_{1}=1 / 4, a_{2}=1 / 5, a_{3}=a_{4}=a_{5}=0$. It is clear that the conditions of Theorem 12 are satisfied. Therefore, $f$ has a fixed point $x=0$.

\section{Acknowledgments}

The authors would like to acknowledge the financial support received from Ministry of Higher Education, Malaysia, under the Research Grant no. ERGS/1/2011/STG/UKM/01/13. The authors thank the referee for his/her careful reading of the paper and useful suggestions.

\section{References}

[1] Y. J. Cho, "Fixed points for compatible mappings of type $(A), "$ Mathematica Japonica, vol. 18, pp. 497-508, 1993.

[2] Y. J. Cho, H. K. Pathak, S. M. Kang, and J. S. Jung, "Common fixed points of compatible maps of type $(\beta)$ on fuzzy metric spaces," Fuzzy Sets and Systems, vol. 93, no. 1, pp. 99-111, 1998.

[3] L. G. Huang and X. Zhang, "Cone metric spaces and fixed point theorems of contractive mappings," Journal of Mathematical Analysis and Applications, vol. 332, no. 2, pp. 1468-1476, 2007.

[4] G. Jungck, Y. J. Cho, and P. P. Murthy, "Compatible mappings of type $(A)$ and common fixed points," Mathematica Japonica, vol. 38, no. 2, pp. 381-390, 1993.

[5] A. Kaewkhao, W. Sintunavarat, and P. Kumam, "Common fixed point theorems of c-distance on cone metric spaces," Journal of Nonlinear Analysis and Application, vol. 2012, Article ID jnaa00137, 11 pages, 2012.

[6] J. S. Vandergraft, "Newton's method for convex operators in partially ordered spaces," SIAM Journal on Numerical Analysis, vol. 4, pp. 406-432, 1967.

[7] L. Ćirić, M. Abbas, R. Saadati, and N. Hussain, "Common fixed points of almost generalized contractive mappings in ordered metric spaces," Applied Mathematics and Computation, vol. 217, no. 12, pp. 5784-5789, 2011.

[8] I. Altun and G. Durmaz, "Some fixed point theorems on ordered cone metric spaces," Rendiconti del Circolo Matematico di Palermo, vol. 58, no. 2, pp. 319-325, 2009.
[9] I. Altun, B. Damjanović, and D. Djorić, "Fixed point and common fixed point theorems on ordered cone metric spaces," Applied Mathematics Letters, vol. 23, no. 3, pp. 310-316, 2010.

[10] Z. Kadelburg, M. Pavlović, and S. Radenović, "Common fixed point theorems for ordered contractions and quasicontractions in ordered cone metric spaces," Computers \& Mathematics with Applications, vol. 59, no. 9, pp. 3148-3159, 2010.

[11] B. S. Choudhury and N. Metiya, "Fixed point and common fixed point results in ordered cone metric spaces," Analele Stiintifice ale Universitatii Ovidius Constanta, vol. 20, no. 1, pp. 55-72, 2012.

[12] W. Shatanawi, "Partially ordered cone metric spaces and coupled fixed point results," Computers \& Mathematics with Applications, vol. 60, no. 8, pp. 2508-2515, 2010.

[13] H. K. Nashine, Z. Kadelburg, and S. Radenović, "Coupled common fixed point theorems for $w^{*}$-compatible mappings in ordered cone metric spaces," Applied Mathematics and Computation, vol. 218, no. 9, pp. 5422-5432, 2012.

[14] R. P. Agarwal, W. Sintunavarat, and P. Kumam, "Coupled coincidence point and common coupled fixed point theorems lacking the mixed monotone property," Fixed Point Theory and Applications, vol. 2013, article 22, 2013.

[15] Y. J. Cho, R. Saadati, and S. Wang, "Common fixed point theorems on generalized distance in ordered cone metric spaces," Computers \& Mathematics with Applications, vol. 61, no. 4, pp. 1254-1260, 2011.

[16] W. Sintunavarat, Y. J. Cho, and P. Kumam, "Common fixed point theorems for $c$-distance in ordered cone metric spaces," Computers \& Mathematics with Applications, vol. 62, no. 4, pp. 1969-1978, 2011.

[17] Y. J. Cho, Z. Kadelburg, R. Saadati, and W. Shatanawi, "Coupled fixed point theorems under weak contractions," Discrete Dynamics in Nature and Society, vol. 2012, Article ID 184534, 9 pages, 2012.

[18] N. Hussain and M. H. Shah, "KKM mappings in cone b-metric spaces," Computers \& Mathematics with Applications, vol. 62, no. 4, pp. 1677-1684, 2011.

[19] H. Aydi, M.-F. Bota, E. Karapinar, and S. Mitrović, "A fixed point theorem for set-valued quasi-contractions in b-metric spaces," Fixed Point Theory and Applications, vol. 2012, article 88, 2012.

[20] A. S. Cvetković, M. P. Stanić, S. Dimitrijević, and S. Simić, "Common fixed point theorems for four mappings on cone metric type space," Fixed Point Theory and Applications, vol. 2011, Article ID 589725, 15 pages, 2011.

[21] M. P. Stanić, A. S. Cvetković, S. Simić, and S. Dimitrijević, "Common fixed point under contractive condition of Cirics type on cone metric type spaces," Fixed Point Theory and Applications, vol. 2012, article 35, 2012.

[22] M. H. Shah, S. Simić, N. Hussain, A. Sretenović, and S. Radenović, "Common fixed points theorems for occasionally weakly compatible pairs on cone metric type spaces," Journal of Computational Analysis and Applications, vol. 14, no. 2, pp. 290-297, 2012.

[23] $\mathrm{H}$. Huang and $\mathrm{S}$. Xu, "Fixed point theorems of contractive mappings in cone b-metric spaces and applications," Fixed Point Theory and Applications, vol. 2012, article 220, 2012.

[24] G. Jungck, S. Radenović, S. Radojević, and V. Rakočević, "Common fixed point theorems for weakly compatible pairs on cone metric spaces," Fixed Point Theory and Applications, vol. 2009, Article ID 643840, 13 pages, 2009. 


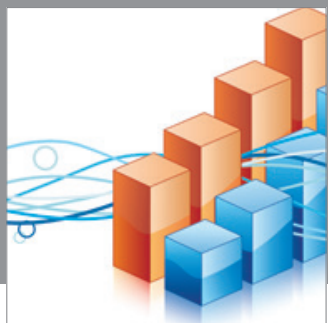

Advances in

Operations Research

mansans

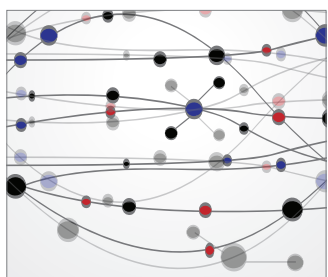

The Scientific World Journal
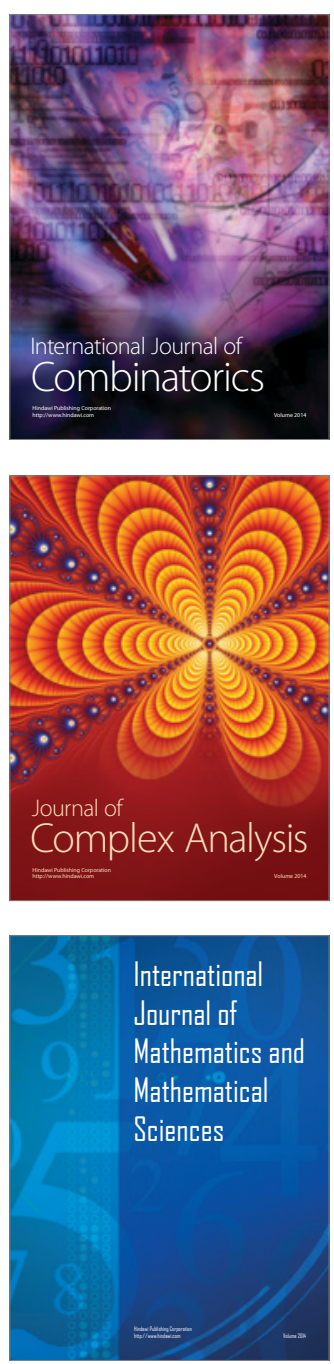
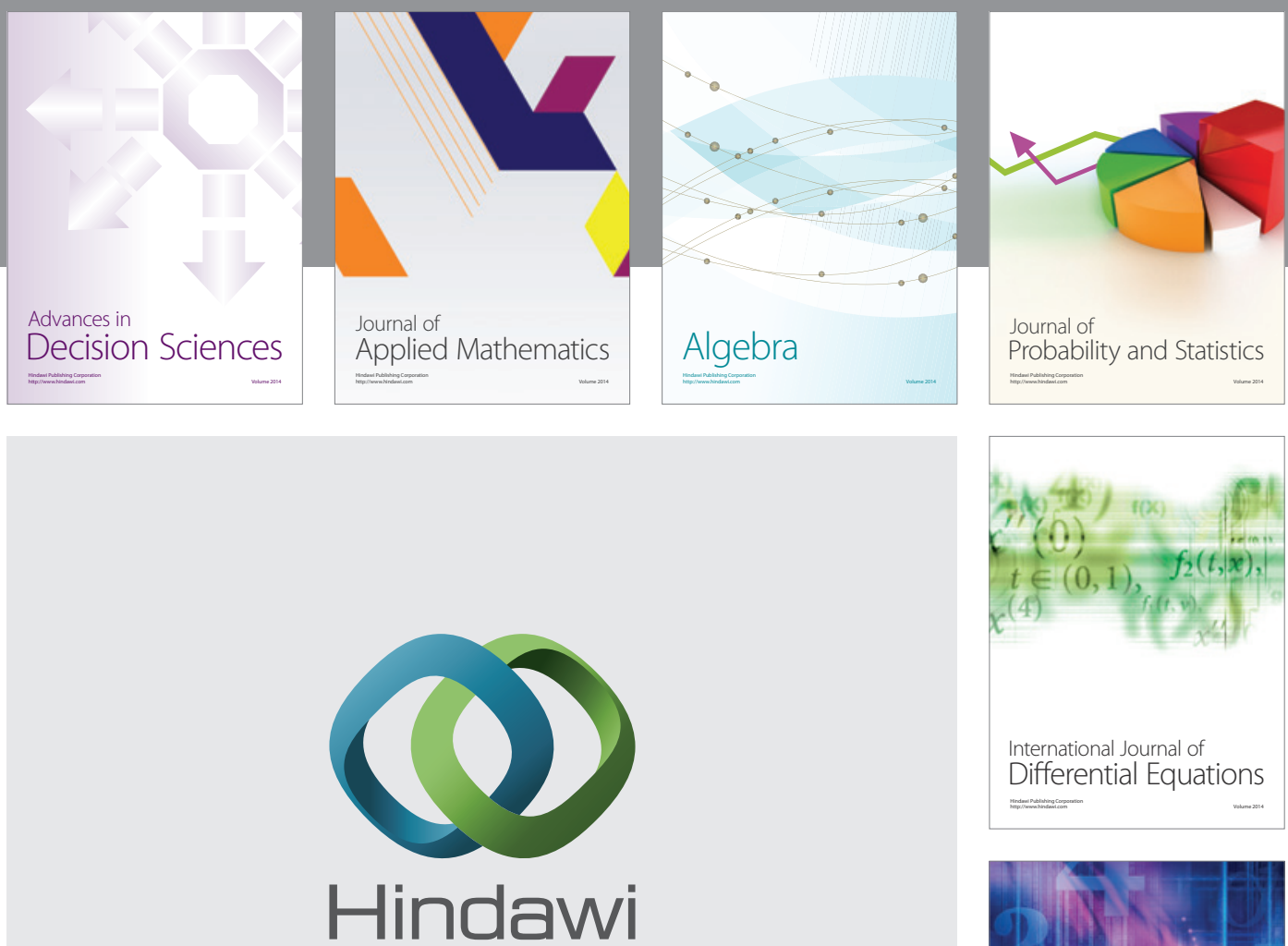

Submit your manuscripts at http://www.hindawi.com
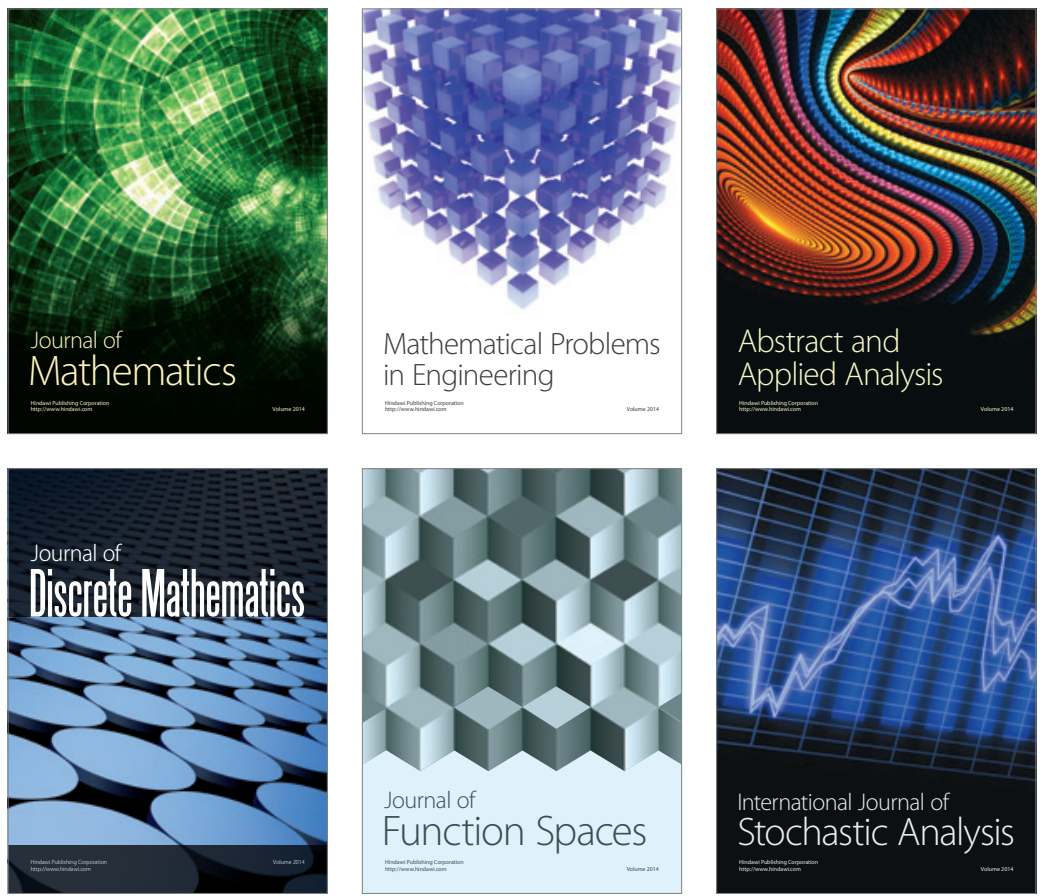

Journal of

Function Spaces

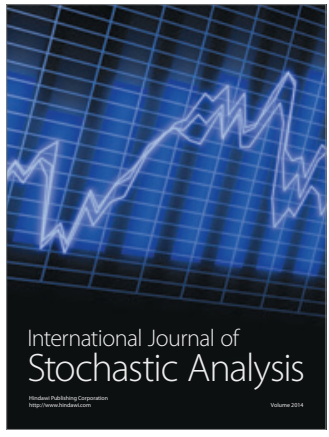

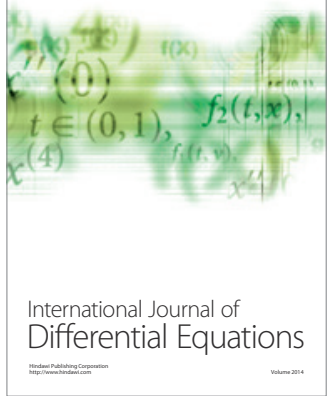
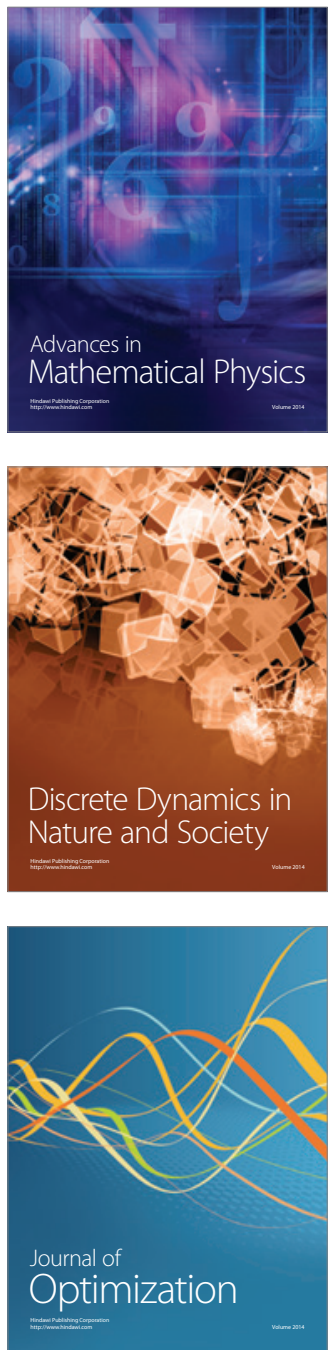